\title{
EVIDENCIAÇÃO E ANÁLISE DE CARGA TRIBUTÁRIA: UM ESTUDO EM EMPRESAS BRASILEIRAS DO SETOR DE ENERGIA ELÉTRICA
}

\author{
TAX BURDEN DISCLOSURE AND ANALYSIS: A STUDY IN BRAZILIAN \\ COMPANIES OF ELECTRIC ENERGY SECTOT
}

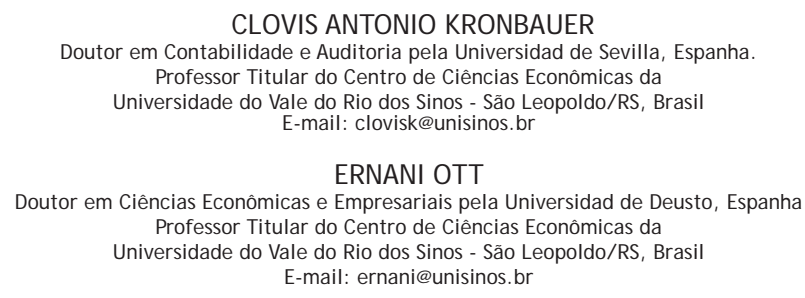

\author{
MARCOS ANTONIO SOUZA \\ Doutor em Controladoria e Contabilidade pela Universidade de São Paulo \\ Professor Titular do Centro de Ciências Econômicas da \\ Universidade do Vale do Rio dos Sinos - São Leopoldo/RS, Brasil \\ E-mail: marcosas@unisinos.br \\ CESAR J OSÉ COLLET \\ Mestre em Ciências Contábeis pela Universidade do Vale do Rio dos Sinos \\ Professor do Curso de Graduação em Ciências Contábeis da Faplan \\ Passo Fundo/ RS \\ E-mail: cesar@colpaz.com.b
}

\section{RESUMO}

O objetivo do artigo é analisar a carga tributária evidenciada por empresas brasileiras do setor de energia elétrica no ano de 2006. Primeiramente se avalia se as empresas cumprem com as normas que regulam a evidenciação da carga tributária, para na sequiência, quantificar e avaliar fatores que possam explicar a variabilidade da referida carga evidenciada. A motivação do estudo relaciona-se à expressividade e reflexos da carga tributária na condução e resultado dos negócios. Os dados foram coletados nas demonstrações contábeis de 17 empresas listadas na Revista Exame - Melhores \& Maiores, edição 2007, divulgadas no site da CVM. Trata-se de uma pesquisa documental, com abordagem qualitativa e quantitativa. Para descrever as formas de evidenciação utilizou-se a análise de conteúdo. Na análise quantitativa a carga tributária evidenciada, utilizouse a estatística descritiva, a correlação e análise de variância - anova. Os resultados da análise descritiva da evidenciação revelam que: as informações tributárias são pouco evidenciadas, sem divulgação aberta ou separada dos tributos; a carga tributária é identificada com maior freqüência na demonstração de resultado e as companhias não apresentam um mesmo padrão de divulgação. Analisando a quantificação dos tributos evidenciados, observa-se uma grande variabilidade na carga tributária identificada. Esta variabilidade possui relação direta com a atividade preponderante das empresas, num nível de significância estatística de $99 \%$. Num intervalo de confiança de $90 \%$, há relevância entre as diferenças das médias de carga tributária evidenciadas, quando se classifica as empresas de acordo com o valor do Patrimônio Líquido e por níveis de Liquidez Circulante.

Palavras-chave: Carga Tributária; Evidenciação; Setor de Energia Elétrica.

\section{ABST RACT}

This article aims to analyze the tax burden disclosed in 2006 by Brazilian companies of electric energy sector. It first assesses whether companies have complied with the rules governing the discl osure of the tax burden to the sequence, quantifying and assessing factors that might explain the variability disclosed burden. The motivation of the study is associated to the relevance and consequences of the tax burden on the businesses conduction and results. Data were collected from financial statement of 17 companies listed in the Revista Exame - Melhores e Maiores, 2007 edition, published in the CVM website. This is a documentary research, with qualitative and quantitative analysis. To describe the forms of disclosure used the content analysis. The quantitative analysis demonstrated the tax burden; we used descriptive statistics, correlation and analysis of variance - ANOVA. The results of descriptive analysis of the disclosure reveals indicate that: taxes information are little disclosed, without specific details about the tributes, the tax burden is identified more frequently in the income statement and the companies does not present a same standard of spreading. Analyzing the quantification of the tax disclosed, there are identified a great variability in the tax burden. This variability has a direct relationship with the company's main activities, a significance statistic level of $99 \%$. A confidence interval of $90 \%$, there are important differences between the average tax burden evidenced when it ranks companies according to the value of equity and the current ratio.

Key words: Tax Burden; Disclosure; Electric Energy Sector. 


\section{INTRODUÇÃO}

Desde meados da década de 1990, o setor elétrico brasileiro vem passando por um processo de reestruturação, cujo objetivo é aumentar a eficiência nas atividades de distribuição e transmissão de energia. Tais reformas foram baseadas no tripé competição, privatização e regulação, visando à introdução gradual de competitividade nos segmentos. As empresas passaram por um processo de desverticalização e privatização, estimulando a eficiência econômica mediante mecanismos de regulação (MARTINS e SENJU, 2007).

As dificuldades para assegurar a competitividade e a eficiência no setor levaram a uma reformulação do processo, adotando-se um novo modelo para o setor, instituído pela Lei $n^{\circ} 10.848 / 2004$, a qual regula a comercialização de energia. Tal modelo visava assegurar a expansão da geração de energia elétrica, provocando a necessidade de captação de recursos para a realização de elevados investimentos, sendo o mercado de ações uma das fontes de financiamento. Assim, além de buscar a maximização das receitas e a minimização dos custos, as companhias passaram a ter que atender às novas necessidades do mercado de capitais, requerendo melhor disponibilização de informações contábeis.

Existem várias formas e níveis de evidenciação de informações contábeis ao mercado. Isso é relevante, pois a omissão de um fato material pode provocar alteração no comportamento decisório do usuário da informação. ludícibus (2004) menciona que a informação qualitativa é difícil de ser avaliada por envolver julgamentos subjetivos e acrescenta que é difícil estabelecer quando uma informação deixa de ser importante no processo decisório, de forma que justifique a omissão de sua evidenciação.

A divulgação de informações sobre as atividades relevantes do processo de gestão é tão importante quanto o lucro e os retornos obtidos. É o caso, por exemplo, da gestão tributária. Padoveze (2003) assinala que o desenvolvimento da gestão de impostos pela controladoria nas empresas, impõe-se pela natural tendência de a contabilidade dispor e utilizar as informações relativas aos impostos, levando os gestores desta atividade a exercerem uma função de apoio e assessoria aos demais gestores da organização.

A gestão tributária consiste no acompanhamento sistemático de todos os tributos na empresa, compreendendo um processo no qual o controller é o responsável pela estruturação de sistemas de informação que dêem suporte à gestão da empresa. Dessa forma, na implantação de um sistema de informações, a contabilidade procura captar entre os métodos de evidenciação aquele que melhor supra as necessidades do processo de gestão. A evidenciação e o objetivo principal da contabilidade estão ligados pelo fato de que as informações divulgadas devem ser transparentes e úteis ao processo decisório. Estes aspectos aplicam-se também a evidenciação da carga tributária das empresas (PADOVEZE, 2003).

Diante desse cenário, apresenta-se a seguinte questão de pesquisa: Qual a relação existente entre a carga tributária evidenciada por empresas brasileiras do setor de energia elétrica com as respectivas variáveis financeiras, econômicas e de tamanho dessas empresas?

Assim, a partir dessa questão de pesquisa, o objetivo geral do estudo é identificar a relação que possa existir entre a carga tributária evidenciada por empresas brasileiras do setor de energia elétrica, com variáveis representativas do posicionamento financeiro, econômico e de tamanho das empresas.

Para que se possa atingir o objetivo geral e responder ao problema de pesquisa, são estabelecidos os seguintes objetivos intermediários: a) realizar análise descritiva da evidenciação e da carga tributária apresentada nas demonstrações contábeis das empresas da amostra; b) avaliar se as formas de evidenciação atendem as normas contábeis específicas do setor; c) identificar, mensurar e analisar a carga tributária evidenciada pelas empresas estudadas.

A relevância do estudo está na análise da evidenciação e mensuração da carga tributária, importante elemento do processo decisório e pouco tratado nessa esfera. Discutir 
a evidenciação da carga tributária das companhias abertas do setor estudado pode contribuir para uma possível redução da assimetria informacional entre gestores e investidores, contribuindo para que os investidores também tenham essas informações quando da alocação de recursos. Além disso, e conforme destacam Amaral, Olenike e Viggiano (2008), a elevada carga tributária constitui-se em fator de impacto nos resultados e na situação financeira das empresas. Sendo assim, é relevante identificar se essa carga tributária guarda relação com variáveis econômicas e financeiras das empresas estudadas.

\section{FUNDAMENTAÇÃO TEÓRICA}

\subsection{DIVULGAÇÃO DE INFORMAÇÕES CONTÁBEIS}

A dinâmica do mercado financeiro tem exigido maior velocidade na divulgação das informações. Recursos eletrônicos, como a Internet, representam um canal de divulgação que potencializa as oportunidades na melhoria da qualidade das informações fornecidas, significando um aumento no poder de disseminação e acessibilidade de informações.

Magalhães Filho e Silva (2005), em pesquisa com empresas que disponibilizam informações ao mercado, constataram que a informação é um dos principais pilares das boas práticas de governança e que as empresas estão aumentando a utilização da internet como meio de relacionamento com investidores, proporcionando maior transparência ao mercado.

Pereira (2004) investigou o nível de divulgação de empresas com base no banco de dados da Fipecafi, entre 1996-2001. Os resultados indicam que companhias de menor tamanho têm baixo nível de divulgação de informações. Talvez isso se deva ao alto custo de divulgação ou à menor necessidade de acesso a determinados instrumentos de dívida ou de captação.

No âmbito da divulgação, conforme destacado por Aquino e Santana (1992), outro aspecto da informação está associado às dimensões de forma e conteúdo. O problema fundamental neste aspecto é escolher a forma que apresenta de maneira mais eficaz os conteúdos; ou seja, a forma também determina as possibilidades de divulgação do conteúdo da informação.

Quanto ao aspecto qualitativo da evidenciação, diversos estudostêm sido desenvolvidos visando identificar os atributos da informação. Nesse contexto, destacam-se as contribuições do estudo de Ponte et al (2007), feito com base na análise das demonstrações contábeis de 95 empresas, referentes ao exercício de 2002, e de 119 empresas, do exercício de 2005. 0 objetivo foi identificar as mudanças percebidas na evidenciação de informações obrigatórias, não-obrigatórias e avançadas praticadas pelas sociedades anônimas no Brasil. Ao final da pesquisa revelou-se, quanto às informações obrigatórias, a não-ocorrência de melhoria das práticas de discl osure das companhias estudadas.

Com relação às informações contábeis de natureza avançada e não-obrigatória, propugnadas pelas práticas de governança corporativa, verificou-se um avanço na sua evidenciação pelas empresas analisadas. Constatou-se, nesse caso, que as empresas dispensavam atenção especial à divulgação de suas práticas de responsabilidade social e do Balanço Social, das Demonstrações do Fluxo de Caixa (DFC) e do Valor Adicionado (DVA).

Apesar das contribuições de todos os estudos citados, nota-se que a análise da evidenciação e mensuração da carga tributária de empresas, foco deste estudo, não foram por eles tratados. 


\subsection{DEMONSTRAÇÕES CONTÁBEIS - ASPECTOS LEGAIS E CONCEITUAIS}

As demonstrações contábeis devem ser apresentadas de acordo com a legislação vigente, atendendo os princípios e normas contábeis e respeitando os dispositivos da Lei ${ }^{\circ}$ 6.404/76, da Lei no 11.638/ 07 e da MP 449/2008. As alterações mais recentes na legislação societária, a esse respeito, referem-se a: (1) substituição da Demonstração de Origens e Aplicações de Recursos - DOAR, pela Demonstração dos Fluxos de Caixa - DFC; e (2) obrigatoriedade de elaboração da Demonstração do Valor Adicionado - DVA.

A DVA, conforme Blatt (2001, p. 153), "tem como objetivo principal informar o valor da riqueza criada pela empresa e a forma de sua distribuição". J á a DFC, conforme Matarazzo (2003) é uma demonstração de grande utilidade, pois quase sempre os problemas de insolvência ou liquidez ocorrem por falta de uma adequada administração do fluxo de caixa.

A DFC e a DVA também estão previstas no manual de contabilidade instituído pela Agência Nacional de Energia Elétrica (ANEEL). Além dessas duas demonstrações, a ANEEL, por meio da Resolução no 444/ 01, exige a elaboração da Demonstração do Resultado por Atividades (DRA), em complemento às demais demonstrações exigidas pela lei societária.

Visando possibilitar a comparação entre os organismos e normas mencionados, apresenta-se no Quadro 1 a lista das demonstrações contábeis obrigatórias.

\begin{tabular}{|l|c|c|c|c|}
\hline \multicolumn{1}{|c|}{ Descrição } & CVM & ANEEL & Lei & Lei \\
\hline Balanço Patrimonial (BP) & SIM & SIM & SIM & S1. 638/07 \\
Demonstração do Resultado do Exercício (DRE) & SIM & SIM & SIM & \\
Demonstração das Mutações do Patrimônio Líquido & SIM & SIM & SIM & \\
(DMPL) & SIM & SIM & SIM & \\
Demonstração das Origens e Aplicações de Recursos & SIM & SIM & SIM & \\
(DOAR) & & SIM & & SIM \\
Notas Explicativas & & SIM & & SIM \\
Demonstração do Valor Adicionado (DVA) & & SIM & & \\
Demonstração dos Fluxos de Caixa (DFC). & & & & \\
Demonstração do Resultado por Atividades (DRA) & & & & \\
\hline
\end{tabular}

Quadro 1: Exigências sobre demonstrações contábeis requeridas

\subsection{O PAPEL DO DISCLOSURE PARA O MERCADO DE CAPITAIS}

A relação entre discl osure e mercado de capitais constitui elemento importante para o desenvolvimento dos negócios em particular e da economia em geral, ao mesmo tempo em que é útil ao crescimento e competitividade internacional das companhias.

Para Assaf Neto (1999), o mercado de capitais assume papel relevante no processo de desenvolvimento econômico, dado que é o grande municiador de recursos permanentes para a economia. Isso decorre da ligação que se estabeleceu entre os que têm capacidade de poupança e aqueles carentes de recursos de longo prazo, dado o déficit de investimentos. Lopes (2001) ratifica tal entendimento, ao relatar que o mercado financeiro, de uma forma geral, é um dos maiores usuários da informação por intermédio de analistas, corretoras, investidores institucionais, bancos de investimentos etc.

Lanzana (2004) destaca que há empresas envolvidas em atitudes de divulgação de informações para buscar diferenciação em relação às demais, particularmente para angariar maiores recursos dos investidores. O objetivo delas é serem avaliadas de forma mais adequada, mantendo relacionamentos favoráveis com o mercado, visando futuras emissões 
de títulos.

Myers e Majluf (1984) advertem que a existência de assimetria informacional torna a oferta de financiamentos ou ações mais cara para os acionistas. Por isso, os gestores são incentivados a prover informações adicionais, aumentando o disclosure voluntário, visando reduzir o problema de assimetria de informações e diminuir o custo do financiamento. Este entendimento é corroborado por Medeiros e Quinteiro (2005), que analisaram uma amostra de 30 empresas brasileiras e 40 ações negociadas, visando identificar a possível influência da evidenciação na volatilidade das ações. Os resultados revelam que maiores níveis de evidenciação implicam na redução da percepção de risco pelo mercado, incentivando novos negócios.

Procianoy e Rocha (2002, p. 1) compartilham com a idéia e afirmam que "as decisões de investimento são tomadas pelos investidores de acordo com a quantidade e qualidade de informações a respeito das empresas disponíveis a eles e ao mercado financeiro".

\subsection{CONSIDERAÇÕES GERAIS SOBRE A ESTRUTURA TRIBUTÁRIA BRASILEIRA}

Existe atualmente uma grande discussão no Brasil a respeito do peso da carga tributária. Tal discussão, no entanto, não é recente na medida em que se observa um contínuo crescimento da relação arrecadação/PIB. Wagner (1883 apud MUSGRAVE e PEACOCK, 1994, p.1-15 ) já destacava a existência desta relação contínua, a qual se tornou conhecida na literatura econômica como a "Lei de Wagner".

Para Amaral, Olenike e Viggiano (2008), a realidade tributária brasileira é complexa, trazendo um significativo custo financeiro ao contribuinte e causando a constante insegurança de se estar ou não cumprindo com todas as obrigações fiscais. Algumas razões para tal são:

a) a existência de cerca de 60 tributos cobrados no Brasil, entre impostos, taxas e contribuições;

b) as inúmeras obrigações acessórias (aproximadamente 97) que uma empresa deve cumprir para estar em dia com o fisco: declarações, formulários, livros, guias etc.;

c) a cumulatividade dos tributos: multi-incidência sobre uma mesma base de cálculo e várias vezes na cadeia produtiva, denominada efeito cascata.

Sobre esse último item, pode-se denominá-lo de Efeito Cascata Vertical, dada a incidência de um tributo sobre o valor de demais. A COFINS incide sobre o ICMS, o INSS, 0 IRPJ e a Contribuição Social, e assim por diante.

\subsection{CARACTERÍSTICAS DO SETOR DE ENERGIA ELÉTRICA BRASILEIRO}

A regulação do setor elétrico brasileiro inicia com o Código de Águas, de 1934, via Decreto 24.643. Em 1993 houve a revisão desta legislação, sendo introduzidas profundas alterações por leis e decretos. Foi promulgada a lei das concessões $n-8.987 / 1995$ que regula o artigo 175 da Constituição Federal e institui regras para a licitação das concessões, as tarifas e os contratos de concessão. Posteriormente, foi sancionada a Lei 9.074/ 1995.

O setor tem como segmentação: (1) geração; (2) transmissão; (3) distribuição; (4) comercialização. Os segmentos assim se diferenciam (SANTANA, 2004):

a) Geração: atividade aberta à competição na comercialização de energia elétrica e, mesmo não estando regulada, tem seus direitos e obrigações contidos nos contratos de concessão ou na autorização, nos termos da legislação vigente.

b) Transmissão: as redes de transmissão agora se constituem em vias de uso aberto, utilizadas por qualquer agente, pagando a devida remuneração ao 
proprietário. Isso deve estimular o ingresso de novos geradores e consumidores. 0 agente de transmissão tem como principal função garantir o livre acesso às suas redes de transmissão.

c) Distribuição: a distribuição é regulada técnica e economicamente pela ANEEL e, assim como as redes de transmissão, deve conceder liberdade de acesso a todos os agentes do mercado. Todo consumidor localizado na zona geográfica de abrangência da distribuidora tem o direito de conectar-se à rede de distribuição e a empresa é obrigada a prestar o serviço, independentemente de ele comprar energia dela ou de qualquer outra comercializadora.

d) Comercialização: na reestruturação do setor surgiu a figura do comercializador de energia, responsável pela compra, importação, exportação e venda de energia elétrica a outros comercializadores ou a consumidores, com os preços livremente negociados. Nesta atividade aberta à competição o cliente final tem caráter concorrencial, cabendo-Ihe escolher a empresa autorizada para a compra de energia, negociando preços, montantes e revenda de excedentes.

\subsection{TRIBUTOS INCIDENTES NO SETOR DE ENERGIA ELÉTRICA}

As atividades empresariais do setor de energia elétrica estão expostas a uma série de tributos, a exemplo do que ocorre com as outras atividades. No Quadro 2 são apresentados os tributos incidentes sobre o setor nas três esferas de governo (federal, estadual, municipal).

\begin{tabular}{|c|c|c|c|c|c|}
\hline Tributos & $\begin{array}{c}\text { Natureza } \\
\text { Jurídica }\end{array}$ & Competência & Regime & $\begin{array}{c}\text { Base de } \\
\text { Cálculo }\end{array}$ & $\begin{array}{c}\text { Alíquota } \\
(\%)\end{array}$ \\
\hline IRPJ & Imposto & Federal & Cumulativo & Lucro & 15 \\
\hline CSLL & Contribuição & Federal & Cumulativo & Lucro & 9 \\
\hline PIS/ PASEP & Contribuição & Federal & Misto & Faturamento & $\begin{array}{c}0,65 \text { ou } \\
1,65\end{array}$ \\
\hline COFINS & Contribuição & Federal & Misto & Faturamento & 3 ou 7,6 \\
\hline ICMS & Imposto & Estadual & Não-Cumulativo & Vendas & Variável \\
\hline ISS & Imposto & Municipal & Cumulativo & Serviços & Variável \\
\hline $\begin{array}{c}\text { Imposto de } \\
\text { Importação }\end{array}$ & Imposto & Federal & Cumulativo & - & - \\
\hline IPI & Imposto & Federal & Não-Cumulativo & Vendas & - \\
\hline CIDE & Contribuição & Federal & Cumulativo & - & - \\
\hline INSS & Contribuição & Federal & - & Remuneração & Variável \\
\hline $\begin{array}{c}\text { Salário } \\
\text { Educação }\end{array}$ & Contribuição & Federal & - & - & - \\
\hline FGTS & Contribuição & Federal & - & Remuneração & 8 \\
\hline Sistema S & Contribuição & Federal & - & Remuneração & Variável \\
\hline
\end{tabular}

Quadro 2: Tributos do sistema tributário brasileiro incidente sobre o setor de energia elétrica

Além dos tributos constantes do Quadro 2, incidem ainda sobre as atividades de energia elétrica, os encargos setoriais. Criados por lei, estes encargos são contribuições cobradas dos agentes do setor elétrico e repassadas aos consumidores por meio das Tarifas de Uso do Sistema de Distribuição (TUSD) e da Tarifa de Energia (TE).

Os encargos setoriais são todos os custos específicos do setor elétrico, incluindo subsídios para usinas termoelétricas e para pesquisas de fontes alternativas de energia, para pagar os custos de órgãos reguladores, compensação a Municípios pela exploração da água, pela eventual subtração de terra em face de inundações provocadas pelas barragens etc.

De acordo com Bandeira (2008), os principais encargos setoriais de energia elétrica, 
são os apresentados no Quadro 3.

\begin{tabular}{|c|l|}
\hline Sigla & \\
\hline RGR & Reserva Global de Reversão \\
\hline CFURH & Compensação Financeira pela Utilização de Reção \\
\hline CCC & Conta de Consumo de Combustíveis \\
\hline TFSEE & Taxa de Fiscalização dos Serviços de Energia Elétrica \\
\hline CDE & Conta de Desenvolvimento Energético \\
\hline ECE & Encargo de Capacidade Emergencial \\
\hline P\&d & Pesquisa e Desenvolvimento Científico e Tecnológico \\
\hline PROINFA & Programa de Incentivo às Fontes Alternativas de Energia Elétrica \\
\hline ONS & Operador Nacional do Sistema Elétrico \\
\hline ESS & Encargo dos Serviços do Sistema \\
\hline
\end{tabular}

Quadro 3: Principais encargos setoriais de energia elétrica

Estes encargos setoriais, juntamente com os tributos apresentados no Quadro 2, formam a carga tributária incidente sobre as atividades do setor de energia elétrica.

\subsection{EVIDENCIAÇÃO DOS TRIBUTOS E ENCARGOS NO SETOR DE ENERGIA ELÉTRICA}

Conforme Gallo (2007), dada a diversidade dos sistemas tributários nos países, não há consenso sobre como mensurar a carga tributária incidente sobre esse setor de atividade. Gallo entende que ao se tornar transparente a carga tributária, se está contribuindo para a obtenção de uma realidade compatível com a essencialidade desse produto.

Lanzana (2004) menciona que no contexto brasileiro o foco fiscal da contabilidade pode suscitar dúvidas se de fato as empresas estão motivadas a apresentar resultados otimistas ou a abrir uma maior quantidade de informações, visto que o interesse primordial das empresas é minimizar a carga tributária. Em países como Austrália, Estados Unidos e Inglaterra, as organizações são motivadas a apresentar os resultados mais otimistas possíveis, a fim de que mais investidores tenham interesse em adquirir suas ações ou títulos de dívida.

A ANELL (2007) descreve os tipos de tributos que devem ser enquadrados sob o título de cada categoria, o que deveria permitir evidenciar os tributos e encargos setoriais do setor de energia elétrica classificados nas demonstrações contábeis.

\subsection{ESTUDOS ANTERIORES INERENTES AO TEMA DA PESQUISA}

Silva (2004) analisou o nível de evidenciação voluntária de 21 empresas do setor, examinando o Relatório de Administração, as Notas Explicativas e o Parecer de Auditoria das demonstrações contábeis referentes ao exercício 2002, bem como as respostas ao questionário enviado às empresas selecionadas. As análises revelaram um elevado número de empresas praticando evidenciação voluntária, com ênfase na DFC e DVA $(95,2 \%)$, Balanço Social $(85,7 \%)$, políticas de responsabilidade social $(80,95 \%)$, resultado por atividade $(71,4 \%)$, EBITDA $(66,7 \%)$. Em todas as 21 empresas pesquisadas encontrou-se uma média de oito informações de divulgação voluntária.

Com relação à mensuração da carga tributária, Gallo (2007) destaca as seguintes metodologias preconizadas internacionalmente:

1. A mensuração das cargas tributárias estatutárias e efetivas, segundo Lammerson (2002). Esta metodologia é criticada por Jacobs e Spengel (1999), por ser inexata e por superestimar a carga tributária efetiva; 
2. A determinação da carga tributária se expressa, considerando o montante total de receitas tributárias em relação ao PIB, ou seja, a relação Impostos/ PIB;

3. A carga tributária medida pelas alíquotas médias de impostos (ATR: Average tax rates), pela qual, segundo Jacobs e Spengel (1999), todos os tributos incidentes e pagos são divididos por um rendimento econômico, ou uma renda definida legalmente; e

4. O calculo das alíquotas marginais, modelo desenvolvido por King e Fullerton, no qual se calcula o diferencial entre as taxas de retorno marginal antes e pós-impostos.

A Receita Federal do Brasil alterou em 2008, a metodologia para o cálculo da carga tributária bruta anual, ou seja, o total de impostos e tributos recolhidos pela União, estados e municípios em relação ao Produto Interno Bruto (PIB). 0 enfoque econômico deu lugar ao jurídico-orçamentário, com adaptação a padrão internacional. Assim, adota-se a forma de cálculo da Organização para a Cooperação e Desenvolvimento Econômico (OCDE), que avalia os tributos de acordo com a base de incidência. 0 método anterior considerava "imposto por imposto", segundo ele (RODRIGUES, 2008).

Mesmo assim, segundo a OCDE (2001), o sistema tributário brasileiro é muito complexo apresentando com principais problemas: as distorções ocasionadas pelo sistema cumulativo das contribuições sociais; o excessivo peso dos impostos federais e estaduais sobre o valor agregado juntamente com as diferentes alíquotas destes impostos; e, a pouca utilização dos impostos diretos. Estes fatores, também dificultam a mensuração da carga tributária, tanto a nível macro, como a nível micro, ou seja, por empresas ou setores.

No que se refere à mensuração da carga tributária das empresas, a adoção de metodologias preconizadas internacionalmente pode ter restrições em sua aplicação. Para Mydew (2001), a pesquisa sobre tributos corporativos em particular, requer a combinação de conhecimentos de natureza institucional e de teoria econômica, e nexte contexto, os pesquisadores contábeis possuem um bom preparo.

Para Jacobs e Spengel (1999), os melhores indicadores para analisar os impactos da tributação sobre o comportamento dos investimentos são os conceitos que vislumbram 0 futuro, destacando-se a taxa marginal efetiva e a taxa média efetiva.

Gallo (2007), em sua Tese Doutoral, propõe que as metodologias para cálculo da carga tributária devam estar amparadas nas definições da Teoria Contábil, ou seja, com base nos conceitos de receitas, despesas, ativos e passivos. Assim o autor propõe que a metodologia de cálculo da carga tributária das empresas seja realizada com base na:

- Demonstração do Valor Adicionado - DVA, quando se estará calculando a carga tributária sobre o valor adicionado gerado pelas empresas, o qual está intrinsecamente relacionado com a apuração do agregado macroeconômico, denominado Produto Nacional; e

- Demonstração do Resultado do Exercício - DRE, visto que as informações contidas na mesma, quando elaborada de forma analítica, permitem a mensuração da carga efetiva da empresa, ou num estudo mais amplo de um determinado setor de atividade.

Já com relação ao setor de energia elétrica, Souza (2007) examinou questões de investimentos neste setor, com análise nas áreas de estrutura de mercado, processo de regulação e avaliação de risco. Menciona, entre outros fatores, que a noção de precisão estaria relacionada também ao grau de eficiência informacional de mercado.

Para concluir esta seção, cabe mencionar PricewaterhouseCoopers (2007), que apresenta fórmula para o cálculo da carga tributária e dos encargos setoriais. As pesquisas relativas à carga tributária sobre as empresas do setor no Brasil, e os respectivos encargos setoriais, apontam para um crescimento, no período $2002-2006$, de 10,4\% na carga tributária total. 


\section{ASPECTOS METODOLÓGICOS DO ESTUDO}

\subsection{CLASSIFICAÇÃO DA PESQUISA}

Quanto à natureza, segundo Silva e Menezes (2001), esta pesquisa classifica-se como aplicada, pois seus resultados, envolvendo as informações contábeis, podem ser apropriados para aplicação nas empresas e utilizadas nas decisões de usuários internos e/ ou externos.

Quanto à abordagem do problema a pesquisa classifica-se como quantitativa, pois se utiliza técnicas estatísticas para alcançar seu objetivo de análise. Já na parte inicial do estudo empírico está presente a característica qualitativa, por meio da análise descritiva de conteúdo dos dados constantes das demonstrações contábeis.

Quanto aos objetivos a pesquisa é descritiva e explicativa, uma vez que se descrevem as práticas de evidenciação das empresas e se identificam os fatores que possam explicar as diferenças na carga tributária evidenciada pelas empresas estudadas.

Quanto aos procedimentos técnicos a pesquisa é classificada como documental e ex-post facto. Documental porque se vale da seleção, organização e obtenção de dados de documentos que ainda não foram tratados para o objeto que se pretende estudar; e ex-post facto porque o experimento com os dados tabulados se dá depois que os fatores ocorreram.

\subsection{POPULAÇÃO, AMOSTRA E PERÍODO DE ANÁLISE}

A população de análise refere-se ao grupo das 50 maiores empresas, por vendas, do setor de serviços, da revista Melhores e Maiores, edição 2007. Dentre as 50 empresas, 29 são do setor de energia elétrica, que constituem objeto desse estudo.Para compor a amostra foram escol hidas as 25 maiores empresas, na ordem decrescente do valor de vendas. Destas 25 empresas foram excluídas 2 empresas por serem holdings e outras 5 por não terem sido localizadas as suas demonstrações contábeis no site da CVM. Assim, a amostra final para análise, está composta por 17 companhias, conforme consta do Quadro 4. Este número é considerado suficientemente representativo para fins deste estudo, pois representa $58,6 \%$ das 29 maiores empresas do setor.

\begin{tabular}{|c|c|c|c|}
\hline Empresa / Sede & Classif. & Empresa / Sede & Classif. \\
\hline AES Eletropaulo, São Paulo, SP & $1 \underline{a}$ & CEMIG GT, Belo Horizonte, MG & $10 \underline{a}$ \\
\hline $\begin{array}{c}\text { CEMIG Distribuição, B. Horizonte, MG } \\
\text { LIGHT SESA, Rio de J aneiro, RJ }\end{array}$ & $2 \underline{a} a$ & CPFL - Piratininga, Campinas, SP & $11 \underline{a}$ \\
\hline CPFL - Paulista, Campinas, SP & $4 \underline{a}$ & CRACTEBEL Energia, Florianópolis, SC & $12^{a}$ \\
\hline COELBA, Salvador, BA & $5 \underline{a}$ & CESP, São Paulo, SP & $13^{\underline{a}}$ \\
\hline CHESF, Recife, PE & $6 \underline{a}$ & COELCE, Fortaleza, CE & $14^{\underline{a}}$ \\
\hline ELEKTRO, CampinaS, SP & $7 \underline{a}$ & CEEE - GT, Porto Alegre, RS & $16^{\underline{a}}$ \\
\hline AMPLA CERJ, Niterói, RJ & $8 \underline{a}$ & AES Sul, Porto Alegre, RS & $17 \underline{a}$ \\
\hline CELPE, Recife, PE & $9 \underline{a}$ & & \\
\hline
\end{tabular}

Quadro 4: Empresas do setor de energia elétrica - amostra estudada 


\subsection{COLETA E TRATAMENTO DOS DADOS}

Os dados foram coletados diretamente nas demonstrações contábeis postadas no site da CVM, a saber: balanço patrimonial (BP), demonstração do resultado do exercício (DRE), notas explicativas (NE), demonstração dos fluxos de caixa (DFC), demonstração do resultado por atividade (DRA) e demonstração do valor adicionado (DVA). As notas explicativas também constituem importante fonte dos dados analisados.

Primeiramente as informações obtidas foram tabuladas e avaliadas no sentido de verificar o reconhecimento e a evidenciação dos tributos e encargos setoriais, comparandoas com a Resolução ANEEL $n^{\circ}$ 444/01, além de identificar as diferenças e similaridades nas informações divulgadas, no sentido de analisar a qualidade da evidenciação realizada.

Na seqüência, os dados quantitativos foram tabulados em planilhas de forma a identificar e classificar os tributos e os encargos setoriais evidenciados nas demonstrações contábeis, para que se pudesse mensurar a carga tributária. A partir das demonstrações contábeis também foram obtidos os dados das variáveis financeiras, econômicas e de tamanho das empresas, utilizadas para explicar os diferentes percentuais de carga tributária evidenciada pelas empresas da amostra.

\subsection{DESCRIÇÃO DOS PROCEDIMENTOS ESTATÍSTICOS}

Para identificar os aspectos que caracterizam os grupos de empresas com diferentes níveis de carga tributária evidenciada, as empresas foram ordenadas segundo variáveis de tamanho, situação financeira e econômica.

O tamanho está representado por três variáveis: o valor do Ativo, do Patrimônio Líquido (PL) e da Receita Bruta (RB). Nesse estudo utilizou-se o logaritmo natural (LN) dos valores absolutos destes itens. A situação financeira está representada pelas variáveis Liquidez Corrente (LC) e Endividamento (Endivid), enquanto que a situação econômica está refletida nas variáveis Retorno sobre o Patrimônio Líquido (RsPL) e Lucratividade Líquida (Lucr. Liq.). Segundo Matarazzo (2003), as fórmulas de cálculo destes índices são:

a) Liquidez Corrente (LC) = Ativo Circulante $\div$ Passivo Circulante;

b) Endividamento (Endivid.) = Passivo Exigível $\div$ Ativo Total;

c) Retorno sobre o Patrimônio Líquido (RsPL) = Lucro Líquido $\div$ Patrimônio Líquido;

d) Lucratividade Líquida (Lucr. Liq.) = Lucro Líquido $\div$ Receita Líquida.

As diferenças na carga tributária evidenciada pelas empresas são identificadas por meio da simples comparação entre elas. Na sequência as empresas foram ordenadas em função de cada uma das variáveis escolhidas. Primeiramente se apresenta a estatística descritiva de todas as varáveis e na seqüência mede-se o grau de correlação existente entre as variáveis, visando identificar, a partir da definição de Stevenson (1986), até que ponto os valores da carga tributária evidenciada pelas empresas da amostra estão relacionados com as variáveis selecionadas.

A partir do grau de correlação, procede-se a análise da variabilidade da carga tributária evidenciada, ordenando a mesma de acordo com os indicadores referidos e explicados. Assim, a carga tributária estará sempre segregada em dois grupos, sendo o ponto de divisão a média geral da variável utilizada para ordenar a carga tributária.

Exemplificando, considera-se o ordenamento da carga tributária segundo a variável LN Ativo, ou seja, as empresas da amostra são divididas em dois grupos: um grupo com LN Ativo menor que a média da amostra e outro grupo com LN Ativo maior que essa média. A partir desta classificação, procede-se a identificação da carga tributária média de cada grupo de empresas e, por meio de análise de variância (ANOVA), segundo expressa Lapponi 
(2005), determina-se se as médias destes dois grupos são iguais ou se podem ser consideradas diferentes.

Este procedimento é repetido com todas as variáveis que apresentam um coeficiente de correlação significativo em relação à carga tributária, buscando assim identificar qual ou quais destas variáveis são características para a determinação de uma maior ou menor carga tributária evidenciada. Por fim, realiza-se análise semelhante, segregando as empresas segundo sua atividade preponderante, buscando, assim, um fator adicional para explicar a maior ou menor carga tributária média evidenciada.

As ferramentas utilizadas para a realização dos testes estatísticos foram o Microsoft Excel e o Econometric Views (Eviews).

\section{APRESENTAÇÃO, ANÁLISE E INTERPRETAÇÃO DOS DADOS}

\subsection{EVIDENCIAÇÃO DA CARGA TRIBUTÁRIA DAS EMPRESAS}

A primeira parte da análise avalia a evidenciação da carga tributária das empresas estudadas. Para isso, foi necessário identificar e descrever as informações evidenciadas nas notas explicativas, em função da impossibilidade de se identificar tais dados somente com base nos balanços e nas demonstrações de resultado, por serem estes relatórios sintéticos.

Com base nesta análise, foi elaborado o Quadro 5, no qual constam as demonstrações contábeis que tiveram evidenciação em Notas Explicativas. A partir deste quadro, constatase que as dezessete empresas da amostra, realizaram evidenciação adicional em Notas Explicativas da seguinte forma:

- 14 empresas apresentaram evidenciação adicional da DRE,

- 11 companhias evidenciaram a DVA,

- 12 empresas evidenciaram a DFC, e

- 13 empresas divulgaram a DRA.

Constatou-se que somente 6 empresas evidenciaram em notas explicativas todas as demonstrações nas quais se pode identificar, com mais clareza, sua carga tributária.Pelas exigências normativas da ANEEL, a evidenciação de informações relativas à DFC, DVA e DRA é considerada como obrigatória para os relatórios emitidos a partir do exercício 2003.

Contudo, no Quadro 5 percebe-se que somente 64,7\% das empresas (11 de 17) apresentam evidenciação relativa à DVA e 12 à DFC. Quanto a DRA, verifica-se que 4 empresas não a evidenciaram, apesar da sua obrigatoriedade, o que pode ser justificado pelo fato de tais empresas explorarem atividade única.

Considerando a obrigatoriedade de evidenciação adicional destas três demonstrações, verifica-se que, das 17 empresas, somente 6 cumpriram integralmente esta exigência da ANEEL, enquanto que as demais 11 companhias (64,7\%) não obedeceram à exigência normativa.

Quanto à DRE, cabe ressaltar que esta consta das demonstrações contábeis de todas as empresas da amostra. Mesmo assim, o estudo revela que $82,4 \%$ das empresas apresentaram divulgação adicional, em anexo nas Notas Explicativas, mesmo não sendo esta uma evidenciação obrigatória de acordo com a ANEEL. 


\begin{tabular}{|c|c|c|c|c|c|}
\hline Empresas / Sede & DRE & DVA & DFC & DRA & Total de Sim \\
\hline 10 - AES Eletropaulo & Sim & Sim & Sim & Não & 3 \\
\hline 2- CEMIG Distribuiç̃o & Sim & Sim & Sim & Não & 3 \\
\hline 3 - LIGHT SESA & Sim & Não & Sim & Sim & 3 \\
\hline 4ㅇ - CPFL - Paulista & Não & Sim & Sim & Não & 2 \\
\hline $50-$ COELBA & Sim & Sim & Sim & Sim & 4 \\
\hline $6 \circ-$ CHESF & Sim & Não & Não & Sim & 2 \\
\hline 70 - ELEKTRO, & Sim & Sim & Sim & Sim & 4 \\
\hline $8 \cong A M P L A$ CERJ & Sim & Não & Não & Sim & 2 \\
\hline 9o - CELPE & Sim & Sim & Sim & Sim & 4 \\
\hline 100 - CEMIG GT & Sim & Sim & Sim & Sim & 4 \\
\hline 11ㅇ - CPFL - Piratininga & Não & Sim & Sim & Sim & 3 \\
\hline 12ㅇ - TRACTEBEL & Não & Sim & Sim & Não & 2 \\
\hline $13 \cong-$ CELG & Sim & Não & Não & Sim & 2 \\
\hline 140 - CESP & Sim & Sim & Sim & Sim & 4 \\
\hline 150 - COELCE & Sim & Não & Não & Sim & 2 \\
\hline 160 - CEEE - GT & Sim & Sim & Sim & Sim & 4 \\
\hline 170 - AES Sul & Sim & Não & Não & Sim & 2 \\
\hline Total de Sim & 14 & 11 & 12 & 13 & 50 \\
\hline
\end{tabular}

Quadro 5: Demonstrações contábeis com evidenciação adicional em notas explicativas

Continuando a análise, e com vistas a identificar a carga tributária evidenciada pelas empresas, identificaram-se os dados relacionados aos tributos incidentes sobre as operações das empresas estudadas, nas seguintes demonstrações contábeis: DRE, DVA e DRA. A carga tributária das empresas está apresentada no Quadro 6, no qual também está identificada a forma de evidenciação da referida carga e a atividade preponderante (principal) de cada empresa.

\begin{tabular}{|c|c|c|c|c|}
\hline Clas. & Empresa & $\begin{array}{l}\text { Atividades } \\
\text { Principais }\end{array}$ & $\begin{array}{c}\text { Forma de Evidenciação } \\
\text { da Carga Tributária }\end{array}$ & $\begin{array}{l}\text { Carga Tributária Relativa } \\
\text { (Tributos / Receita Bruta) }\end{array}$ \\
\hline 10 & AES Eletropaulo & $\mathrm{De} C$ & Não divulgou a DRA & 0,3594 \\
\hline 20 & CEMIG & De C & Não divulgou a DRA & 0,4601 \\
\hline 30 & LIGHT SESA & $\mathrm{DeC}$ & Analítica & 0,4144 \\
\hline 40 & CPFL Paulista & De C & Não divulgou a DRA & 0,4651 \\
\hline 50 & COELBA & De C & Segregada e Analítica & 0,4593 \\
\hline 60 & CHESF & G e T & Analítica & 0,1706 \\
\hline 79 & ELEKTRO & De C & Segregada e Analítica & 0,4304 \\
\hline 80 & AMPLA CERJ & D e C & Segregada e Analítica & 0,4048 \\
\hline 90 & CELPE & De C & Analítica & 0,4366 \\
\hline 100 & CEMIG GT & G e T & Sintética & 0,3354 \\
\hline 110 & CPFL Piratininga & De C & Sintética & 0,4410 \\
\hline $12^{0}$ & TRACKBEL & G e T & Não divulgou a DRA & 0,2239 \\
\hline 130 & CELG & G e T & Analítica & 0,4789 \\
\hline 140 & CESP & $\mathrm{Ge} \mathrm{T}$ & Segregada e Sintética & 0,2769 \\
\hline 150 & COELCE & D e C & Analítica & 0,4144 \\
\hline 160 & CEEE-GT & G e T & Analítica & 0,2696 \\
\hline $17^{0}$ & AES SUL & De C & Segregada e Analítica & 0,4175 \\
\hline \multicolumn{2}{|c|}{ Carga Tributária Média } & $* * * * *$ & $* . * * * *$ & 0,3799 \\
\hline
\end{tabular}

Quadro 6: Evidenciação da carga tributária das empresas e atividades preponderantes

Observando os dados do Quadro 6, verifica-se que das 17 empresas estudadas, 11 $(64,7 \%)$ tem como atividades preponderantes a Distribuição e Comercialização (D e C) de Energia Elétrica, enquanto que as demais 6 empresas $(35,5 \%)$ têm como atividades preponderantes a Geração e Transmissão (G e T). 
Outro aspecto identificado no Quadro 6 diz respeito às formas de evidenciação da carga tributária das empresas, merecendo destaque: (1) a falta de uniformidade nas características da evidenciação realizada pelas empresas; (2) a falta de divulgação da DRA por parte de 4 empresas, apesar das exigências da ANEEL; (3) o fato de somente 4 empresas $(23,5 \%$ da amostra) realizarem uma evidenciação segregada e analítica, situação que possibilita identificar de forma adequada a carga tributária evidenciada.

Quando analisado por atividade preponderante, as empresas classificadas com D e C apresentam a média da carga tributária situada em 42,75\%, muito acima das empresas classificadas como G e T, cuja média ficou em $29,26 \%$. Para quantificar a carga tributária relativa, evidenciada pelas empresas estudadas, utilizou-se a mesma fórmula adotada pela PricewaterhouseCoopers (2007), ou seja:

\section{Somatório dos Tributos e Encargos Evidenciados $\div$ Receita Operacional Bruta}

A partir da quantificação desta carga tributária, conforme Quadro 6, constatamse grandes diferenças nos índices identificados, pois se tem uma carga mínima de 0,1706 $(17,06 \%)$ e uma carga máxima de $0,4789(47,89 \%)$. Constata-se que a carga tributária média evidenciada é de 0,3799 (37,99\%) em relação à Receita Bruta.

Em 2007, a Pricewaterhousecoopers calculou a carga tributária do setor de energia elétrica em 39,3\%. A carga média identificada nas empresas da amostra, apesar de inferior em 1,31 pontos percentuais em relação àquela calculada em 2007, apresenta-se muito próxima a ela. Isso permite concluir que a carga tributária média identificada nas demonstrações contábeis das empresas estudadas está coerente com os dados desse estudo técnico da Pricewaterhousecoopers.

Dada a significativa variabilidade da carga tributária evidenciada, realizaram-se análises adicionais, utilizando técnicas estatísticas de correlação e análise de variância, ordenando a carga tributária de acordo com as variáveis descritas na seção 3.4 deste estudo.

\subsection{RELAÇÃO ENTRE A CARGA TRIBUTÁRIA EVIDENCIADA E AS VARIÁVEIS SELECIONADAS}

Com o intuito de identificar uma possível relação entre a carga tributária evidenciada pelas empresas e as variáveis selecionadas, apresentam-se, primeiramente, os dados relativos à estatística descritiva das varáveis analisadas, conforme Tabela 1.

\section{Tabela 1: Estatística descritiva das variáveis analisadas}

\begin{tabular}{|c|c|c|c|c|c|c|c|c|}
\hline Est Descrit & $\begin{array}{c}\text { Carga } \\
\text { Trib }\end{array}$ & LN Ativo & LN PL & LN RB & LC & Endivid & RsPL & $\begin{array}{c}\text { Lucr. } \\
\text { Líq. }\end{array}$ \\
\hline Média & 0,3799 & 15,4589 & 14,1858 & 15,1237 & 0,9631 & 0,6881 & 0,2351 & 0,1075 \\
\hline Mediana & 0,4144 & 15,3942 & 14,1141 & 14,9240 & 1,0081 & 0,6891 & 0,1862 & 0,1219 \\
\hline Desvio pad & 0,0925 & 0,7633 & 1,0506 & 0,5199 & 0,3685 & 0,1492 & 0,3673 & 0,1350 \\
\hline Mínimo & 0,1706 & 14,3428 & 12,3404 & 14,5359 & 0,2522 & 0,3721 & $-0,2783$ & $-0,1617$ \\
\hline Máximo & 0,4789 & 16,7949 & 16,2538 & 16,2448 & 1,6991 & 0,8727 & 1,3280 & 0,4066 \\
\hline Variância & 0,0086 & 0,5826 & 1,1038 & 0,2703 & 0,1358 & 0,0223 & 0,1349 & 0,0182 \\
\hline Curtose & 0,1198 & $-0,8295$ & 0,6002 & 0,0409 & $-0,1135$ & 0,0219 & 4,2248 & 0,6227 \\
\hline Assimetria & $-1,0905$ & 0,2689 & 0,2156 & 1,0776 & $-0,0602$ & $-0,7575$ & 1,4979 & 0,0804 \\
\hline Propab & 0,2429 & 0,6727 & 0,9433 & 0,2482 & 0,9365 & 0,4926 & 0,0050 & 0,9873 \\
\hline Contagem & 17 & 17 & 17 & 17 & 17 & 17 & 17 & 17 \\
\hline
\end{tabular}

Com relação aos dados que compõem a Tabela 1, observa-se que a carga tributária média identificada é de 0,3799, enquanto que a carga mínima é de 0,1706 e a máxima equivale a 0,4789. Estes dados revelam a existência de grande variabilidade entre as médias, remetendo o estudo à aplicação das técnicas estatísticas de correlação e análise de 
variância.

Cabe destacar que pela probabilidade apresentada na Tabela 1, somente a variável RsPL não pode ser considerada como distribuição normal. Mesmo que a probabilidade de distribuição normal de algumas variáveis como a carga tributária $(0,2429)$ e LN RB $(0,2482)$ não seja tão significativa, não se pode afirmar que estas não sejam distribuições normais.

Por haver distribuições normais e não normais no conjunto de variáveis, os testes estatísticos utilizados para caracterizar os diferentes níveis de carga tributária partem da análise de correlação e, a partir desta, se realiza a análise de variância (ANOVA).

No primeiro passo da análise apresenta-se a Tabela 2, na qual estão representados os coeficientes de correlação entre as varáveis estudadas.

Tabela 2 - Quadro de correlação entre as variáveis analisadas

\begin{tabular}{l|r|r|r|r|r|r|r|r}
\hline Correlação & Carga Trib & LN Ativo & LN PL & LN RB & LC & Endivid & RsPL & Lucr Líq \\
\hline Carga Trib & 1 & & & & & & & \\
\hline LN Ativo & $-0,370254$ & 1 & & & & & & \\
\hline LN PL & $-0,499610$ & 0,899331 & 1 & & & & & \\
\hline LN RB & 0,225574 & 0,517342 & 0,238389 & 1 & & & & \\
\hline LC & 0,469509 & 0,135256 & 0,045292 & 0,566105 & 1 & & & \\
\hline Endivid & 0,660598 & $-0,432119$ & $-0,768789$ & 0,297317 & 0,194336 & 1 & & \\
\hline RsPL & 0,284797 & $-0,355423$ & $-0,295529$ & 0,031264 & 0,201625 & 0,092281 & 1 & \\
\hline Lucr Líq & $-0,181541$ & $-0,150608$ & 0,123874 & $-0,035073$ & 0,224155 & $-0,465110$ & 0,569235 & 1 \\
\hline
\end{tabular}

Verifica-se pelos dados da Tabela 2 que a variável que possui maior grau de correlação com a carga tributária evidenciada é o Endividamento (Endivid.: 0,660598). Apesar de não apresentar a mesma significância, outras variáveis também têm correlação próxima a $50 \%$, como é o caso do LN PL e da LC. Mesmo assim, para a análise de variância não se pode descartar outros níveis de correlação, o que conduz à opção de analisar em cada grupo de variáveis aquelas com maior correlação.

\subsubsection{COMPARAÇÃO DA CARGA TRIBUTÁRIA COM O TAMANHO DAS EMPRESAS}

Para explicar os diferentes níveis de carga tributária evidenciada pelas empresas em função dos seus tamanhos, as variáveis inicialmente analisadas no quadro de correlação (Tabela 2) é o logaritmo natural (LN) do Ativo Total, do Patrimônio Líquido e da Receita Bruta. Verifica-se que LN PL e LN Ativo registram maior correlação (respectivamente -0,4996 e $-0,3702)$. Percebe-se que a relação é negativa, o que pode sugerir que nas menores empresas (por PL e Ativo) a carga tributária seja maior.

Para identificar se a carga tributária nas empresas menores é maior que nas empresas maiores, aplicou-se a análise de variância. Assim, a análise se realiza com empresas de Ativo (LN Ativo) menor que a média, e com empresas de Ativo maior que a média. Com relação ao $\mathrm{PL}, 0$ critério utilizado foi o mesmo. Os testes de análise de variância entre a carga tributária e o tamanho das empresas revelam como resultado os dados apresentados nas Tabelas 3 e 4.

Apresenta-se na Tabela 3 a comparação entre a carga tributária das empresas com menor valor de Ativo (LN Ativo < Média) com a carga tributária daquelas empresas com maior valor de Ativo. Pelos resultados obtidos, verifica-se que 9 empresas com menor ativo evidenciaram uma carga tributária média de 0,3886 (38,86\% em relação à Receita Bruta), enquanto que as outras 8 empresas com maior valor de ativo evidenciaram carga tributária de 0,3701 (37,01\% em relação à receita Bruta).

Comparando simplesmente as médias das cargas tributárias, poder-se-ia concluir que a carga tributária das 9 empresas com menor valor de ativo fosse maior que a carga tributária 
das demais, que possuem Ativo maior, conforme evidenciado na Tabela 3.

Tabela 3: Anova da carga tributária e ativo das empresas

\begin{tabular}{|c|c|c|c|c|c|c|}
\hline \multicolumn{7}{|c|}{ Anova: fator único $=>$ Carga Tributária x LN Ativo } \\
\hline \multicolumn{7}{|c|}{ RESUMO } \\
\hline Grupo & Cont. & Soma & Média & Variância & & \\
\hline C Trib: Ativo < Med & 9 & 3,4975 & 0,3886 & 0,0069 & & \\
\hline C Trib: Ativo > Med & 8 & 2,9608 & 0,3701 & 0,0115 & & \\
\hline \multicolumn{7}{|c|}{ ANOVA } \\
\hline Fonte da Variação & $S Q$ & $q l$ & $M Q$ & $F$ & valor-P & F crítico \\
\hline Entre Grupos & 0,00145 & 1 & 0,00145 & 0,16057 & 0,69428 & 4,54308 \\
\hline Dentro dos Grupos & 0,13558 & 15 & 0,00904 & & & \\
\hline Total & 0,13703 & 16 & & & & \\
\hline
\end{tabular}

Contudo, ao observar o "F" estatístico calculado, que é igual a 0,16057, percebe-se que este é bem menor que o "F crítico", situado em 4,54308, o que leva a concluir que as médias de carga tributária das empresas não são estatisticamente diferentes nos dois grupos analisados, considerando um intervalo de confiança de 95\%. Pelo "valor-P", pode-se concluir que a probabilidade de que as médias das cargas tributárias dos dois grupos de empresas sejam iguais, está próxima a 69,43\% $(0,69428)$, o que é significativamente alto. Portanto, não se pode afirmar que o tamanho das empresas (valor de Ativo) seja um fator que possa explicar a variabilidade da carga tributária evidenciada pelas mesmas.

Diante do resultado obtido em relação ao tamanho das empresas pelo seu valor de Ativo, cabe analisar se outra medida de tamanho, ou seja, o valor do PL não possui melhor poder de explicação na relação com a referida carga tributária, conforme apresentado na sequência.

Tabela 4: A nova da carga tributária e patrimônio líquido das empresas

\begin{tabular}{|c|c|c|c|c|c|c|}
\hline \multicolumn{7}{|c|}{ Anova: fator único => Carga Tributária x LN PL } \\
\hline \multicolumn{5}{|c|}{ RESUMO } & & \\
\hline Grupo & Cont. & Soma & Média & Variância & & \\
\hline C Trib: $\mathrm{PL}<$ Med & 9 & 3,7621 & 0,4180 & 0,0036 & & \\
\hline C Trib: PL > Med & 8 & 2,6962 & 0,3370 & 0,0115 & & \\
\hline \multicolumn{7}{|c|}{ ANOVA } \\
\hline Fonte da Variação & $S Q$ & $q l$ & $M Q$ & $F$ & valor-P & F crítico \\
\hline Entre Grupos & 0,02778 & 1 & 0,02778 & 3,81398 & 0,06974 & 4,54308 \\
\hline Dentro dos Grupos & 0,10925 & 15 & 0,00728 & & & \\
\hline Total & 0,13703 & 16 & & & & \\
\hline
\end{tabular}

Apresenta-se na Tabela 4 a comparação entre a carga tributária das empresas com menor valor de Patrimônio Líquido ( $\mathrm{LN} \mathrm{PL}<$ Média) com a carga tributária daquelas empresas com maior valor de PL, ou seja, aquelas cujo valor do LN de seus PL está acima do valor médio dos tamanhos das mesmas.

Pelos resultados apresentados na Tabela 4, verifica-se que as 9 empresas com menor $\mathrm{PL}$, evidenciaram uma carga tributária média de 0,4180 (41,80\% em relação à Receita Bruta), enquanto e as outras 8 empresas com maior valor de PL evidenciaram carga tributária de 0,3370 (33,7\% em relação à receita Bruta).

Comparando as médias das cargas tributárias, observa-se que a carga tributária média das 9 empresas com menor valor de PL é 8,1 pontos percentuais maior que a carga tributária das que possuem PL maior que a média da amostra $(0,4180 \times 0,3370)$. Contudo, observando o "F" estatístico calculado em 3,81398, percebe-se que este é um pouco menor que o 
“F crítico", situado 4,54308, o que leva a concluir que as médias de carga tributária das empresas não podem ser consideradas estatisticamente diferentes nos dois grupos anal isados, num intervalo de confiança de $95 \%$. Pelo "valor-P”, pode-se concluir que a probabilidade de que as médias das cargas tributárias dos dois grupos de empresas sejam iguais, está próxima a $6,97 \%(0,06974)$, o que revela que as médias são diferentes quando se diminui o intervalo de confiança para $90 \%$.

Mesmo que não se possa afirmar, num intervalo de confiança de 95\%, que o tamanho das empresas seja um fator que possa explicar a variabilidade da carga tributária por elas evidenciada, observa-se que os valores dos testes estatísticos estão muito próximos de confirmar esta hipótese. E isso pode ser verdadeiro, pois a confirmação ocorre num intervalo de confiança de $90 \%$, ou seja, num nível de confiança de $10 \%$.

\subsubsection{RELAÇÃO CARGA TRIBUTÁRIA X SITUAÇÃO FINANCEIRA E ECONÔMICA DAS EMPRESAS}

Para os fatores relacionados à situação econômica e financeira das empresas analisadas, que possam explicar a variabilidade da carga tributária evidenciada, foram elaboradas as Tabela 5 e 6 apresentadas na sequência.

\begin{tabular}{|c|c|c|c|c|c|c|}
\hline \multicolumn{7}{|c|}{ CARGA TRIBUTÁRIA E SITUACC̃̃O FINANCEIRA DAS I } \\
\hline \multicolumn{7}{|c|}{ Anova: fator único $=>$ Carga Tributária x LC } \\
\hline \multicolumn{5}{|c|}{ RESUMO } & & \\
\hline Grupo & Cont. & Soma & Média & Variância & & \\
\hline C Trib: LC $<$ Med & 8 & 2,6928 & 0,3366 & 0,0132 & & \\
\hline C Trib: LC > Med & 9 & 3,7655 & 0,4184 & 0,0021 & & \\
\hline \multicolumn{7}{|c|}{ ANOVA } \\
\hline Fonte da Variação & SQ & gl & MQ & $\mathrm{F}$ & valor-P & F crítico \\
\hline Entre Grupos & 0,02833 & 1 & 0,02833 & 3,90978 & 0,06668 & 4,54308 \\
\hline Dentro dos Grupos & 0,10870 & 15 & 0,00725 & & & \\
\hline \multicolumn{7}{|c|}{ Anova: fator único => Carga Tributária x Endivid } \\
\hline \multicolumn{5}{|c|}{ RESUMO } & & \\
\hline Grupo & Cont. & Soma & Média & Variância & & \\
\hline C Trib: Endivd $<$ Med & 8 & 2,7379 & 0,3422 & 0,0117 & & \\
\hline C Trib: Endivid > Med & 9 & 3,7204 & 0,4134 & 0,0042 & & \\
\hline \multicolumn{7}{|c|}{ ANOVA } \\
\hline Fonte da Variação & SQ & gl & MQ & $F$ & valor-P & F crítico \\
\hline Entre Grupos & 0,02143 & 1 & 0,02143 & 2,78148 & 0,11610 & 4,54308 \\
\hline Dentro dos Grupos & 0,11559 & 15 & 0,00771 & & & \\
\hline
\end{tabular}

Na Tabela 5 tem-se a comparação entre a carga tributária e os indicadores financeiros Liquidez Corrente (LC) e Endividamento (Endivid.). Com relação à LC, cabe referir que a média geral deste índice na amostra estudada é de 0,96305 (Tabela 1, Seção 4.2). Assim, analisando as 8 empresas abaixo desta média de LC, verifica-se que sua carga tributária média é igual a 0,3366 (33,66\%), enquanto que as demais 9 empresas, com liquidez maior, possuem uma carga tributária de 0,4184 (41,84\% em relação à receita bruta).

Parece ser significativa a diferença entre as médias de carga tributária dos dois conjuntos de empresas. Porém, observando os dados da ANOVA, percebe-se que o "F" calculado é um inferior ao " $\mathrm{F}$ crítico" o que não permite afirmar que a média da carga tributária das empresas com menor liquidez é realmente menor que a média da carga tributária das empresas com maior liquidez, num intervalo de confiança de 95\%. 0 "valor-P" indica a existência de uma probabilidade de igualdade de médias de aproximadamente 6,67\% 
$(0,06668)$, o que é estatisticamente significativo num nível de significância de $10 \%$.

Quanto ao Endividamento, a média da carga tributária das 8 empresas com endividamento menor que a média da amostra $(0,68808$-Tabela 1$)$ é igual a 0,3422 , enquanto que as demais 9 empresas, com endividamento maior, possuem carga tributária média de $0,4184(41,84 \%$ em relação à receita Bruta). É, portanto, verifica-se uma tendência muito semelhante ao que foi encontrado com relação à liquidez.

Contudo, observando os dados da ANOVA, percebe-se que o "F" calculado $(2,78148)$ é significativamente inferior ao "F crítico" $(4,54308)$. Assim, não se pode afirmar que a média da carga tributária das empresas com menor Endividamento seja menor que a média da carga tributária das empresas com maior índice de endividamento, nem mesmo num intervalo de confiança de $90 \%$ (Tabela 5).

Outro fator que poderia explicar as diferenças entre a carga tributária das empresas da amostra, seria a relação com o indicador de Retorno sobre o Patrimônio Líquido (RsPL). A média de RsPL das empresas, conforme a estatística descritiva (Tabela 1, seção 4.2), é de 0,23506. Conforme dados da Tabela 6, as 10 empresas têm um RsPL inferior a esta média, evidenciaram uma carga tributária média de 0,3564 (35,64\%), enquanto que as demais 7 empresas, com rentabilidade maior que a média, evidenciaram carga tributária média de $41,35 \%(0,4135)$ em relação à receita Bruta. Contudo, esta diferença não é estatisticamente significativa, o que fica comprovado pelos cálculos de Anova, nos quais o "F" calculado $(1,62591)$ é bem inferior ao "F Crítico" $(4,54308)$.

Conclui-se, com base nesses dados, também apresentados na Tabela 6, que existe significativa probabilidade de que as médias de carga tributária das empresas com menor e maior rentabilidade não sejam diferentes, o que se comprova pelo valor-P de 0,22167 $(22,17 \%)$.

Tabela 6: Anova da carga tributária e situação econômica das empresas

\begin{tabular}{|c|c|c|c|c|c|c|}
\hline \multicolumn{7}{|c|}{ Anova: fator único => Carga Tributária x RsPL } \\
\hline \multicolumn{5}{|c|}{ RESUMO } & & \\
\hline Grupo & Cont. & Soma & Média & Variância & & \\
\hline C Trib: RsPL < Med & 10 & 3,5641 & 0,3564 & 0,0089 & & \\
\hline C Trib: RsPL > Med & 7 & 2,8942 & 0,4135 & 0,0073 & & \\
\hline \multicolumn{7}{|c|}{ ANOVA } \\
\hline Fonte da Variação & SQ & gl & MQ & $\mathrm{F}$ & valor-P & F crítico \\
\hline Entre Grupos & 0,01340 & 1 & 0,01340 & 1,62591 & 0,22167 & 4,54308 \\
\hline Dentro dos Grupos & 0,12363 & 15 & 0,00824 & & & \\
\hline
\end{tabular}

Concluída a análise que compara a carga tributária das empresas e os indicadores de tamanho, financeiros e econômicos, resta ainda analisar se a variabilidade da carga tributária evidenciada possui relação com a atividade preponderante das empresas, conforme apresentado na próxima seção.

\subsubsection{RELAÇÃO DA CARGA TRIBUTÁRIA EVIDENCIADA COM A ATIVIDADE PREPONDERANTE}

A atividade preponderante das empresas estudadas está identificada no Quadro 6, da seção 4.1 deste estudo. Para realizar a análise, foi atribuído o número 1 para as 6 empresas que exploram a atividade de Geração e Transmissão ( $G$ e T), enquanto que as 11 empresas, cuja atividade preponderante é a Distribuição e Comercialização ( $D$ e C) de energia elétrica, foram classificadas pelo algarismo 2 .

Para identificar o grau de correlação que pudesse existir entre carga tributária evidenciada e atividade preponderante, procedeu-se ao cálculo do coeficiente respectivo, com auxílio da ferramenta Excel, sendo o resultado obtido igual a 0,718561. Assim, verificase que a carga tributária evidenciada pelas empresas está correlacionada em $71,9 \%$ com 
a atividade preponderante por estas desenvolvida. Com este significativo coeficiente de correlação, cabe analisar se existe diferença significativa entre as médias de carga tributária em cada grupo de empresas por atividade preponderante (Tabela 7).

Tabela 7: Anova de carga tributária e atividade preponderante

\begin{tabular}{|c|c|c|c|c|c|c|}
\hline \multicolumn{5}{|c|}{ RESUMO } & & \\
\hline Grupo & Contagem & Soma & Média & Variância & & \\
\hline Geração / Transmissão & 6 & 1,7553 & 0,2926 & 0,0114 & & \\
\hline Distribuição / Comercialização & 11 & 4,7030 & 0,4275 & 0,0009 & & \\
\hline \multicolumn{7}{|c|}{ ANOVA } \\
\hline Fonte da variação & $S Q$ & $g l$ & $M Q$ & $F$ & valor-P & F crítico \\
\hline Entre grupos & 0,07075 & 1 & 0,07075 & 16,01283 & 0,00116 & 4,54308 \\
\hline Dentro dos grupos & 0,06628 & 15 & 0,00442 & & & \\
\hline Total & 0,13703 & 16 & & & & \\
\hline
\end{tabular}

Observando os dados da Tabela 7, percebe-se que as 6 empresas cuja atividade principal é a Geração e Transmissão de energia elétrica evidenciaram uma carga tributária média de 0,2926 (29,26\% em relação a receita bruta). Já a carga tributária média evidenciada pela empresas de Distribuição e Comercialização de energia é equivalente a 42,75\% 0,4275 $(42,75 \%)$.

Percebe-se uma carga tributária muito menor nas empresas de geração e transmissão, situação que se confirma estatisticamente pela análise de variância, na qual o " $F$ " calculado é de 16,01283 enquanto que o "F crítico" é bem inferior, situado em 4,54308. Isso serve para afirmar que as médias de carga tributária evidenciada são mesmo diferentes, num nível de significância de $99 \%$, o que pode ser comprovado pelo Valor-P de 0,00116 (0,116\%).

\section{CONSIDERAÇÕES FINAIS}

No atual contexto do setor elétrico brasileiro, as empresas realizam operações cada vez mais sofisticadas e os aspectos estritamente operacionais deixam de ser a única preocupação dos investidores, acionistas e demais usuários. Questões relacionadas com a carga tributária e encargos setoriais ganham importância e ocupam mais espaço no conj unto das informações disponibilizadas aos usuários. Os órgãos de regulamentação de normas contábeis, nacionais e internacionais, enfatizam cada vez mais a necessidade de maior evidenciação e destacam, para esse fim, o papel das demonstrações contábeis.

Os principais resultados deste estudo indicam que, no âmbito das empresas pesquisadas, as informações tributárias são pouco evidenciadas. De fato, os dados relativos aos tributos e encargos do setor não são divulgados de forma separada ou aberta, limitando em muito uma análise mais específica e pormenorizada. Constata-se que a carga tributária se identifica com maior freqüência na demonstração de resultados e que as companhias da amostra não apresentam o mesmo padrão de divulgação.

Nesse sentido, surpreende o descumprimento normativo por grande parte das empresas da amostra, dada a obrigatoriedade de divulgação requerida pela ANEEL para o setor. Isso confirma o entendimento dos estudos citados nas seções 2.1 e 2.3 deste estudo, a respeito de que as empresas relutam em aumentar o nível de disclosure, limitando-se às exigências legais e regulamentares e, quando as cumprem, o fazem apenas satisfatoriamente.

A carga tributária média identificada nas demonstrações contábeis das empresas estudadas é coerente com aquela determinada em estudos técnicos anteriores, tais como 0 da PricewaterhouseCoopers (2007), mas apresenta grandes diferenças entre a menor e maior 
carga evidenciada. Buscando as causas desta grande variação, constata-se que a significativa variabilidade na carga tributária evidenciada pelas empresas da amostra possui relação direta com a atividade preponderante desenvolvida por estas. Neste caso, identificou-se que a maior carga tributária está nas empresas de Distribuição e Comercialização, enquanto a menor nas carga está nas empresas de Geração e Transmissão, fato comprovado estatisticamente.

Também se mostram relevantes, num intervalo de confiança de $90 \%$, as diferenças entre as médias de carga tributária evidenciadas por empresas, quando se classifica as mesmas de acordo com o valor do Patrimônio Líquido e por níveis de Liquidez Circulante. No caso do tamanho por PL, a relação mostra-se negativa, o que pode sugerir maior carga de tributos nas menores empresas. Já no caso da Liquidez, a relação mostra-se positiva, ou seja, empresas com melhor liquidez teriam maior carga tributária. Cabe referir que no caso destes dois índices, mostra-se uma tendência confirmada num intervalo de confiança de $90 \%$.

Com relação às implicações teóricas que o estudo proporciona, cabe ressaltar as questões relativas ao disclosure de informações obrigatórias e voluntárias, visto que os resultados obtidos apontam para deficiência das empresas nesta área. Isto remete à necessidade de maior transparência e compreensão das necessidades dos usuários em obter informações adequadas e úteis ao processo decisório.

Com relação às implicações gerenciais, se põe de manifesto a questão da necessidade do estudo das situações tributárias específicas. Tendo sido o setor de atuação fator determinante na variabilidade da carga tributária das empresas, parece evidente que 0 exame da carga tributária é um aspecto particular de cada empresa, situação que merece atenção dos gestores que buscam nas suas medidas de gestão, maximizar resultados para a empresa.

A relação relevante identificada entre a carga tributária e a liquidez rechaça a idéia muitas vezes propugnada no meio empresarial, de que a elevada carga tributária é fator que decisivamente afeta este aspecto na das empresas. Contudo, isto não afasta a necessidade dos gestores em manter a busca de uma estrutura financeira adequada, justamente para fazer frente aos desembolsos relativos aos tributos incidentes nas operações.

Durante o desenvolvimento deste estudo uma agenda de temas para futuras pesquisas se descortinou, destacando-se dois. O primeiro, agora no âmbito da auditoria e do controle exercido pela ANEEL, corresponde a investigar como ambas tem avaliado o nível de disclosure das empresas quanto ao atendimento tanto das determinações legais quanto das evidenciações voluntárias. 0 segundo, um estudo de natureza explicativa, refere-se a uma investigação mais específica sobre as causas da diferenciação da carga tributárias das empresas do setor, em função da atividade preponderante por elas executada. Acredita-se que esse segundo estudo tem potencial para induzir novas ações de planejamento tributário, no âmbito das empresas, e de incentivos fiscais, no âmbito governamental.

Por fim, espera-se que esse estudo motive os futuros leitores a seguir essa temática nesse setor não muito explorado em estudos científicos.

\section{REFERÊNCIAS}

AMARAL, Gilberto Luiz; OLENIKE, J oão Eloi; VIGGIANO, Letícia M. F. Amaral. Estudo sobre o verdadeiro custo da tributação. IBPT - Instituto Brasileiro de Planej amento Tributário, mai 2008. Disponível em: <http:// www.ibpt.com.br/img/_publicacao/9169/142.pdf >. Acesso em: 10 jul. 2008.

ANEEL - Agência Nacional de Energia Elétrica. Resolução 444/2001. Institui o Manual de Contabilidade do Serviço Público de Energia Elétrica - MCSPEE. 2001. 
. Manual de Contabilidade do Serviço Público de Energia Elétrica. 2007. Disponível em: <www. aneel.gov. br/aplicacoes/leitura_arquivo/arquivos/Manual. pdf >. Acesso: 02 jul. 2008.

AQUINO, W.; SANTANA, A. C. Evidenciação. Caderno de Estudos, 5, São Paulo: FIPECAFI, julho 1992, 40p.

ASSAF NETO, Alexandre. Mercado financeiro. 3.ed. São Paulo: Atlas, 1999.

BANDEIRA, F. P. M. Encargos incidentes sobre as tarifas de energia elétrica. 2008. Disponível em: <www. apache. camara. gov. br/ portal/ arquivos/ Camara/ internet/ publicacoes/ estnottec/ tema16/2005 7981>. Acesso em: 10 jul. 2008.

BLATT, Adriano. Análise de balanços: estrutura e avaliação das demonstrações financeiras e contábeis. São Paulo: Makron Books, 2001.

BRASIL. Decreto no 24.643, de 10 de julho de 1934. Decreta o Código de Águas.

Lei no 6.404, de 15 de dezembro de 1976. Dispõe sobre as Sociedades por Ações.

Lei $\mathbf{n} \mathbf{0} \mathbf{8 . 9 8 7}$, de 13 de fevereiro de 1995. Dispõe sobre o regime de concessão e permissão da prestação de serviços públicos previstos no art. 175 da Constituição Federal, e dá outras providências.

Lei $\mathbf{n} \mathbf{9} \mathbf{9 . 0 7 4}$, de 7 de julho de 1995. Estabelece normas para outorga e prorrogações das concessões e permissões de serviços públicos e dá outras providências.

Lei no 10.848, de 15 de março de 2004. Dispõe sobre comercialização de energia è étrica entre concessionários, permissionários e autorizados de serviços e instalações de energia elétrica, bem como destes com seus consumidores, no Sistema Interligado Nacional.

Lei no 11.638, de 28 de dezembro de 2007. Altera e revoga dispositivos da Lei no $\overline{6} . \overline{0} \overline{4} / \overline{7} 6$ e da Lei $n-6.385 / 76$, e estende às sociedades de grande porte disposições relativas elaboração e divulgação de demonstrações financeiras.

Medida Provisória no 449, de 3 de dezembro de 2008. Altera a legislação tributária féderal relativa ao parcelamento ordinário de débitos tributários, concede remissão nos casos em que especifica, institui regime tributário de transição, e dá outras providências.

EXAME - Melhores e Maiores: as $\mathbf{5 0 0}$ maiores empresas do Brasil, São Paulo: Editora Abril. Ago. 2007. Suplemento.

GALLO, Mauro Fernando. A relevância da abordagem contábil na mensuração da carga tributária das empresas. Tese (Dourado em Contabilidade). FEA/USP. São Paulo, 2007.

IUDíCIBUS, Sérgio. Teoria da Contabilidade. 7.ed. São Paulo: Atlas. 2004.

LANZANA, A. P. Relação entre disclosure e governança corporativa das empresas brasileiras. Dissertação (Mestrado em Administração). Universidade de São Paulo. São Paulo, 2004.

LAPPONI, J uan Carlos. Estatística Usando Excel. 4 ed. São Paulo: Campus, 2005.

LOPES, A. B. A relevância da informação contábil para o mercado de capitais: o modelo de OhIson aplicado a Bovespa. Tese (Doutorado em Contabilidade). FEA/USP. São Paulo, 2001.

MAGALHÃES FILHO, P. A. O.; SILVA, W. M. Determinantes da disseminação voluntária de informações financeiras na internet. RAE-eletrônica, v. 4, 2, Art. 19, jul./ dez. 2005.

MARTINS, E.; SENJ U, E. K. A. A reestruturação do setor elétrico brasileiro nos anos 90 e as 
implicações sobre o segmento da distribuição. Revista de Economia da UEG. v. 3, 2, p.6990, jul./ dez. 2007.

MATARAZZO, Dante Carmine. Análise financeira de balanços. 6 ed. São Paulo: Atlas, 2003.

MEDEIROS, O. R.; QUINTEIRO, L. G. L. Evidenciação contábil e volatilidade dos retornos das ações no Brasil. In: ENANPAD, XXIX 2005. Anais... Brasília: ANPAD, 2005. CD-ROM.

MYERS, S. MAJ LUF, N. Corporate financing and investment decisions when firms have no information that Investors do not have. NBER. Working Paper 1396. 1984. Disponível em: <http://www.nber.org/papers/W1396>. Acesso em: 30 abr. 2008.

MUSGRAVE, Richard A.; PEACOCK, Alan T. Classics in the theory of public finance. Chicago, St. Martin's Press, 1994.

PADOVEZE, C. L. Curso básico gerencial de custos. São Paulo: Pioneira Thomson, 2003.

PEREIRA, M. Antonio. Estudo do nível de divulgação e sua relação com a estrutura de capital em empresas brasileiras. In: ENANPAD XXVIII. 2004. Anais... Curitiba: ANPAD, 2004. CDROM.

PONTE, V. M. Rodrigues; OLIVEIRA, M. Colares; MOURA, Heber; CARMO, R. C. Almeida. Análise das práticas de evidenciação de informações obrigatórias, não obrigatórias e avançadas nas demonstrações contábeis das Sociedades Anônimas no Brasil: um estudo comparativo dos exercícios de 2002 e 2005. Revista Contabilidade e Finanças, v. 18, 45. p. 50-62, 2007.

PRICEWATERHOUSECOOPERS. Carga tributária consolidada - setor elétrico brasileiro- 1999 a 2006. 3.ed. 2007. Disponível em: <http:// www. pwc.com/images/bz/Modelo setor eletrico 04.pdf >. Acesso: 8 jul. 2008.

PROCIANOY, J airo Laser, ROCHA, Carlos Fernando Palco. Disclosure das companhias abertas: um estudo exploratório do departamento de relações com investidores. In: ENANPAD. XXVI. 2002. Curitiba. Anais... Salvador: ANPAD. 2002. CD-ROM.

SANTANA J R., S. C. Importância do papel institucional de uma agência reguladora no desenvolvimento da indústria de energia elétrica no Brasil: caso ANEEL. Dissertação (Mestrado em Engenharia de Produção). Univ. Federal de Santa Catarina, Florianópolis, 2004.

SILVA, José Roque Fagundes. As empresas do setor elétrico brasileiro e os níveis de evidenciações voluntárias das demonstrações contábeis. Dissertação (Mestrado em Contabilidade). Universidade de São Paulo. São Paulo, 2004.

SILVA, Edna Lúcia; MENEZES, Estera Muszkat. Metodologia da pesquisa e elaboração de dissertação. 2.ed. Florianópolis: UFSC/PPGEP/LED, 2001.

SOUZA, Antonio Ricardo. Agências reguladoras e seus modelos de gestão: uma análise na ANEEL e ANATEL. Tese (Doutorado em Administração). Universidade Federal da Bahia. Salvador, 2007.

STEVENSON, William J. Estatística aplicada à administração. São Paulo: Harbra, 1986. 


\section{ENDEREÇOS DOS AUTORES:}

Centro de Ciências Econômicas

Universidade do Vale do Rio dos Sinos

Av. Unisinos, 950 - Cristo Rei

Caixa-Postal 275

Sao Leopoldo, RS - Brasil

93022-000

FAPLAN - Faculdades Planalto Passo Fundo

Rua: Paissandu, 1200

Passo Fundo, RS - Brasil

99010-022 